\title{
Iron Metabolism in Cancer Progression
}

\author{
Stefania Forciniti ${ }^{1}$, Luana Greco ${ }^{1}\left(\mathbb{D}\right.$, Fabio Grizzi ${ }^{2} \mathbb{(}$, Alberto Malesci ${ }^{3}$ and Luigi Laghi $1,4, * \mathbb{C}$ \\ 1 Humanitas Clinical and Research Center, IRCCS, Department of Gastroenterology_Laboratory of Molecular \\ Gastroenterology, Rozzano, 20089 Milan, Italy; stefania.forciniti@humanitasresearch.it (S.F.); \\ luana.greco@humanitasresearch.it (L.G.) \\ 2 Department of Immunology and Inflammation, Humanitas Clinical and Research Center, Via Manzoni 56, \\ Rozzano, 20089 Milan, Italy; fabio.grizzi@humanitasresearch.it \\ 3 Humanitas Clinical and Research Center, IRCCS, Department of Gastroenterology, Rozzano, \\ 20089 Milan, Italy; alberto.malesci@hunimed.eu \\ 4 Department of Medicine and Surgery, University of Parma, 43100 Parma, Italy \\ * Correspondence: luigi.laghi@humanitas.it
}

Received: 6 March 2020; Accepted: 22 March 2020; Published: 24 March 2020

check for updates

\begin{abstract}
Iron is indispensable for cell metabolism of both normal and cancer cells. In the latter, several disruptions of its metabolism occur at the steps of tumor initiation, progression and metastasis. Noticeably, cancer cells require a large amount of iron, and exhibit a strong dependence on it for their proliferation. Numerous iron metabolism-related proteins and signaling pathways are altered by iron in malignancies, displaying the pivotal role of iron in cancer. Iron homeostasis is regulated at several levels, from absorption by enterocytes to recycling by macrophages and storage in hepatocytes. Mutations in HFE gene alter iron homeostasis leading to hereditary hemochromatosis and to an increased cancer risk because the accumulation of iron induces oxidative DNA damage and free radical activity. Additionally, the iron capability to modulate immune responses is pivotal in cancer progression. Macrophages show an iron release phenotype and potentially deliver iron to cancer cells, resulting in tumor promotion. Overall, alterations in iron metabolism are among the metabolic and immunological hallmarks of cancer, and further studies are required to dissect how perturbations of this element relate to tumor development and progression.
\end{abstract}

Keywords: iron; HFE (gene); oxidative stress; macrophages

\section{Introduction}

Iron is an indispensable element for several cellular processes, as many basic functions of the cell rely upon iron. It is chiefly involved in processes such as DNA synthesis, ATP production and oxygen transport. In humans, iron deposits are distributed in macrophages, reticulocytes, liver, and the equilibrium between its absorption and export is controlled in the intestine [1]. Multiple molecules cooperate to maintain iron homeostasis because, if the equilibrium is disrupted, iron can catalyze Fenton reaction and produce reactive oxygen species (ROS) [2]. This event may promote ferroptosis, a non-apoptotic cell death mechanism characterized by iron-dependent generation of lipid peroxidation products $[3,4]$. Iron homeostasis is thus a finely tuned process, both at the systemic and cellular level, which involves incorporation, utilization and storage. Iron binds to transferrin (TF) forming a complex that recognizes the transferrin receptor 1 (TFR-1) on the outer side of cell membrane. This complex is internalized in the endosome by endocytosis, and $\mathrm{Fe}^{3+}$ is reduced to $\mathrm{Fe}^{2+}$ by iron reductase, mainly by members of six-transmembrane epithelial antigen of the prostate (STEP1-4) family [5]. Thereafter, iron is transported in the cytosol mainly via divalent metal-ion transporter 1 (DMT1) by constituting the cytoplasmic labile iron pool (LIP). This now metabolically active iron can be delivered to different cell compartments for a variety of metabolic needs, or otherwise stored in ferritin, a protein complex that 
concentrates iron in an inactive form for later use [6]. An excess of iron can be exported out of the cell through ferroportin, the only known cellular iron efflux pomp which cooperates with ceruloplasmin or hephaestin to maintain cellular iron homeostasis [7]. In this respect, the homeostasis at cellular level is achieved by the system of iron responsive elements-iron regulatory proteins (IREs-IRPs) [8], while at systemic level is maintained by hepcidin, a circulating hormone that regulates iron levels causing degradation of ferroportin (Figure 1) [9]. An increasing number of studies have highlighted the link between dysregulation of iron metabolism and human diseases, including cancer [10-12]. Various iron-related proteins have been related to cancer progression and metastasis, having an altered expression and activity in cancer cells compared with the normal counterpart [13]. Particularly, iron-regulated genes increase their metabolic iron demands needed for both early and late stages of tumor development. In cancer patients, perturbation of iron metabolism contributes to anemia as seen in chronic diseases, due to several factors, among others the secretion of inflammatory factors that reduce erythropoiesis [14]. The involvement of iron in cancer is also described in mice models [15] in which a low-iron diet before inoculating cancer cells delayed tumor growth. Furthermore, it has been shown that tumors can utilize the natural iron deposits in spleen and liver. Consequently, red blood cells recycling and iron storage is compromised, and erythropoiesis reduced. In this review, we provide an overview of iron metabolism, genetic iron overload disorders, and iron-driven molecular mechanisms with respect to cancer progression. In addition, we discuss how the regulation of immune system and iron metabolism are strictly related, so that changes in either one of the two can affect the other.

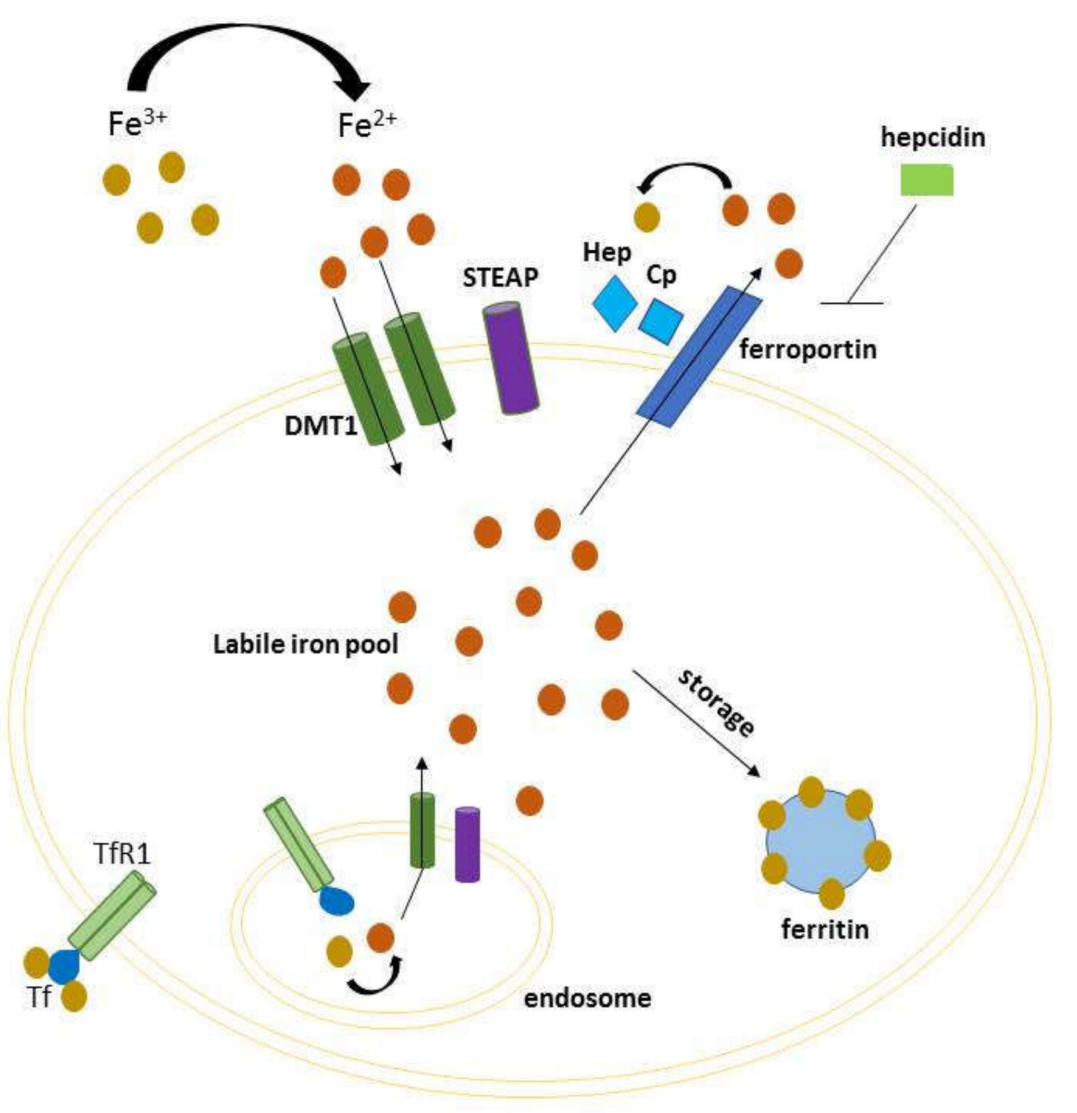

Figure 1. Schematic representation of cellular iron homeostasis. Iron is imported via the divalent metal-ion transporter 1 (DMT1) transporter (requiring STEAP2 activity), or via endocytosis of transferrin receptor 1. Intracellular iron can either constitute the cytoplasmic labile iron pool (LIP, to be delivered to different cell compartments), either be stored in ferritin for later use. The excess of iron is exported through ferroportin, which cooperates with hephaestin and ceruloplasmin, and inhibited by hepcidin. 


\section{Historical Bases}

\subsection{Relationship Between Iron Metabolism and Cancer}

Deregulated iron homeostasis is one of the metabolic hallmarks of malignant cancer cells, in which iron is highly required during all stages of tumor development, survival, proliferation, and metastasis [16]. Being tumor cells strongly dependent on iron for their growth/proliferation, they are more sensitive to iron depletion than normal cells [17]. The pathways of iron metabolism that are deregulated in cancer include processes of uptake-export, storage, and regulation [18]. Generally, transferrin receptor1 (TFR 1) is important for iron uptake and for the regulation of cell growth. It has been demonstrated that cancer cells show a high expression of this receptor compared to normal cells [19]. For this reason, TFR1 affects cancer cell proliferation, migration, invasion, and metastasis and it represents an important target for cancer therapy [20].

Cui et al. found a higher expression of TFR1 in well differentiated colorectal cancers with no lymph node involvement and no distant metastasis than in normal tissues. Furthermore, patients with TFR1-positive expression had increased survival than patients with TFR1-negative expression. Although it has been detected an overexpression of TFR1 in colorectal cancer, the authors demonstrated that a downregulation of TFR1 promoted cell migration and invasion via JAK/STAT pathway [21].

TFR1 is also highly expressed in pancreatic ductal adenocarcinoma. Jeong et al. reported that TFR1 contributed to the mitochondrial respiration and ROS production in human pancreatic cancer cells which are essential in their tumorigenic growth and survival. Moreover, TFR1 expression determined the sensitivity of cells to oxidative stress [22].

It is known that iron reductase, in particular members of STEAP family, are important for iron uptake and iron reduction in the endosome [23]. Several studies demonstrate an altered expression of STEAP 1-4 in different types of tumor such as prostate, breast, pancreatic cancer and glioma [24,25]. In prostate cancer, STEAP2 seems to drive cancer progression by promoting proliferation, migration and invasion and modifying the transcriptional profiles of some genes involved in metastatic process. In this context, Burnell and colleagues demonstrated that decreasing STEAP 2 expression in prostate cancer cells reduces their proliferation, migration and invasion in vitro. Furthermore, analyzing the expression of STEAP 2 in 164 tumor tissues, it has been found an increased expression in tumor tissues compared to normal tissues [26]. A central role in iron storage is carried out by ferritin. In some cases of cancer patients, ferritin is detected in high concentration in plasma, correlating with advanced tumor stage and poor outcome $[27,28]$. Accordingly, increased ferritin levels are found not only in inflammatory diseases, but also in several cancers (e.g., lung carcinoma, pancreatic, and colorectal cancer), suggesting that high ferritin might underlie cancer development and progression [29-31].

The iron efflux is controlled by ferroportin, an iron efflux pump, and by its regulator hepcidin, which appear to be involved in tumorigenesis [32]. In prostate and breast cancer, a reduction of ferroportin expression on cell surface induces an increase of intracellular iron, and is associated with the emergence of an aggressive phenotype [33,34].

Pinnix and colleagues demonstrated that both ferroportin and hepcidin are normally expressed in human breast epithelial cells and tissues. Moreover, the ferroportin expression is strongly reduced in breast cancer cells and tissues compared to normal counterparts, while the overexpression of ferroportin reduced growth of xenografted breast cancer cells in vivo.

Furthermore, the gene expression profiles of around 800 breast cancer patients have reported that a decrease in ferroportin gene expression is correlated with an important reduction in metastasis-free and disease-free survival [35]. Numerous studies have shown that hepcidin contributes to cancer proliferation and progression, then regulating its level to reduce iron pool in tumor cells may be a new strategy in cancer treatment [36].

In colorectal cancer, an increase in intracellular iron is coupled with both an increased expression of import proteins (CYTB, DMT1, and TFR1), and a block in iron export due to aberrant localization of FPN, the loss of which was also associated with more advanced disease [37]. In colorectal cancer 
cells (CaCo-2 and SW480), iron overload cells caused cellular proliferation and E-cadherin repression, suggesting transition towards a mesenchymal states (epithelial to mesenchymal transition, EMT) and loss of adherence. In support of the potential role of iron-regulating proteins in EMT, it should be noted that B2-microglobulin supports metastasis in vivo by interacting with HFE, and its expression in cancer cells drives EMT (decreasing E-cadherin while increasing $N$-cadherin and vimentin). Accordingly, inhibition of both B2-microglobulin and HFE reverts EMT [38]. This aspect should be elucidated in those cancers for which an association has been found with both HFE genotypes (see below) and EMT [39].

\subsection{Hereditary Hemochromatosis, a Genetic Iron-Overload Disorder, and Its Association with Cancer}

Iron homeostasis is often altered by mutations that occur in several genes and that contribute to most iron-related genetic diseases resulting in iron overload or deficiency [40]. Hereditary iron overload, known as hereditary hemochromatosis $(\mathrm{HH})$, is mostly associated with HFE gene mutations, although other genes may be less frequently involved, alike those encoding hepcidin or transferrin receptor 2 [41]. HFE is a MHC class-like protein that controls the expression of hepcidin, a peptide secreted in plasma by the liver that regulates iron distribution at systemic level [42]. HFE interacts with TFR1 to form a complex that is disrupted by binding holotransferrin. Subsequently, HFE cooperates with TFR2 and with the bone morphogenetic protein (Bmp) co-receptor Hemojuvelin, the interaction of which leads to the activation of hepcidin transcription [43]. Mutations in the HFE gene lead to an inability of hepatocytes to detect increased levels of iron and to stimulate hepcidin transcription. Consequently, this results in low hepcidin levels, high ferroportin activity, and excessive absorption of iron from diet resulting in iron overload in liver and other organs [44]. The most common mutations in the HFE gene implicated in the pathogenesis of HH are p.C282Y and p.H63D. C282Y is due to a substitution of tyrosine for cysteine at 282 position in the protein sequence, while H63D is a point mutation that changes histidine to aspartic acid at 63 position [45]. Most patients are homozygous for $\mathrm{C} 282 \mathrm{Y}$ mutation, that is the predominant genetic profile in $\mathrm{HH}$, or compound heterozygous for $\mathrm{C} 282 \mathrm{Y}$ in association with $\mathrm{H} 63 \mathrm{D}$, the latter alone being considered a genetic profile that only predisposes to a mild iron overload. Genetic mutations of H63D in homozygosity represent approximately $1 \%$ of individuals with gene mutation [46]. It has been widely reported that HFE gene mutations are correlated with increased cancer risk [47], the underlying mechanism being that the accumulation of iron induces oxidative DNA damage and free radical activity. The iron-catalyzed free radical reactions cause lipid peroxidation, protein modification and DNA damage. In particular, the H63D polymorphism is associated with an increased risk of several tumors, including hepatocellular carcinoma, breast, colorectal, and pancreatic cancers [48,49]. Beside an inherent increased risk (19-fold) of developing hepatocellular carcinoma [48], carriers of HFE C282Y homozygotes have twice the risk of colorectal (HR 2.28 ; 95\%C.I., 1.22-4.25) and breast cancer compared with individuals without the C282Y variant [50]. Such an increased risk was not detected in these studies for heterozygous HFE variants yet [51], the risk of colorectal cancer might be increased by compound heterozygosity for the HFE mutations (O.R.,3.03; 95\% C.I., 1.06-8.61), although this association could not remain significant after Bonferroni correction for two post hoc tests. Meta-analyses focusing on the issue of the association between cancer and HFE variants, reported conflicting results. In some meta-analysis, $\mathrm{C} 282 \mathrm{Y}$ but not $\mathrm{H63D}$ variant was related to elevated cancer risk [52], including colorectal cancer [53] under recessive model (OR $=2.00,95 \%$ $\mathrm{CI}=1.32-3.04)$, in Caucasians. The latter association was evident for studies concerning more than 500 cases.

However, others have found that also H63D variant could be associated with increased cancer risk, such as gastric cancer (non-cardia, $\mathrm{OR}=1.60, \mathrm{CI}=1.16-2.21$, and intestinal subtype, $\mathrm{OR}=1.82$, $\mathrm{CI}=1.27-2.62$ [ [54]. A similar association has been observed also for pancreatic cancer [55], as HFE rs1799945 (i.e., H63D) was significantly associated with PC risk, with each additional copy of minor allele T being associated with a 1.21-fold increased risk of PC (OR $=1.21,95 \% \mathrm{CI}=1.05-1.39, P=7.72 \times$ $\left.10^{-3}\right)$ in Chinese population including 1000 cases and as many controls. Previously, a European study 
comprising 168 patients with pancreatic adenocarcinoma had failed to detect any significant association with HFE genotype [56]. The linkage between H63D polymorphism and the development of cancer was verified by examining published statistical data through a meta-analysis. This study estimated that H63D variant influences cancer progression, due to altered iron metabolism [57]. Specifically, it has been identified a statistically significant association between H63D polymorphism and hepatocellular carcinoma and pancreatic cancer risk, especially in Asian and African populations [57].

Further studies are needed to clarify the association between HFE genotypes and high risk of gastrointestinal cancers and, whether confirmed, to unravel the correlation with natural history and clinical behavior. As a companion to meta-analysis, in silico data exploration would be of help. This approach has not been used for the above mentioned gastrointestinal cancers, but it has employed to assess the frequency of HFE variants in glioblastoma [58] by comparing the datasets in the TCGA with those of the 1000 genome. Although no differences in survival were reported in this study, it would be of interest to extend such an approach to other cancers, possibly taking into account relevant molecular tumor features. In the case of colorectal cancer, it would be relevant to assess the frequency of HFE genotypes primarily as to tumor MS-status, due to the implications of this molecular phenotype for diagnosis and patient management [59]. Only one report exists as to the association of these polymorphisms as potential modifiers of Lynch syndrome, which reported an increased risk of developing colorectal cancer for H63D homozygotes [60].

\subsection{Mini-Summary}

Available studies indicate that abnormalities in iron homeostasis are among the hallmark of cancer, being traceable at tumor development, progression and metastasis. The main deregulation of iron homeostasis occurs at the level of its uptake-export or storage, thus resulting in overload or deficiency. Furthermore, variants in the HFE gene lead to the accumulation of iron in various organs, sustaining the pathogenesis of hereditary hemochromatosis, coupled to an increased cancer risk due to oxidative damage of DNA and free radical activity, adding these mechanisms to carcinogenesis. Further studies are warranted to better understand the correlation between HFE genotypes and high risk of cancer.

\section{Molecular Mechanisms}

\subsection{The Role of Iron in Oxidative Stress}

Iron is a central element for cell survival and many biological processes, thus its appropriate amount is indispensable for cells. However, when iron is present in excess it can generate reactive oxygen species (ROS), both directly and indirectly [61]. The redox-active iron $\left(\mathrm{Fe}^{2+}\right)$ participates with hydrogen peroxide $\left(\mathrm{H}_{2} \mathrm{O}_{2}\right)$ in the Fenton reaction $\left(\mathrm{Fe}^{2+}+\mathrm{H}_{2} \mathrm{O}_{2} \rightarrow \mathrm{Fe}^{3+}+\bullet \mathrm{OH}+\mathrm{OH}^{-}\right)$directly generating hydroxyl radical and ferric iron $\left(\mathrm{Fe}^{3+}\right)$. This reaction catalyzed by iron produces a large amount of highly reactive hydroxyl radicals that can damage DNA, proteins and lipids through oxidation [62]. Iron associated with DNA induces mutations or single and double strand breaks, while iron bound to proteins can promote a $\mathrm{H}_{2} \mathrm{O}_{2}$-dependent redox signaling. Furthermore, iron is essential in the formation of lipid peroxyl radicals and it can react with lipid peroxides produced by hydroxyl radicals. These lipid peroxyl radicals can become cytotoxic aldehydes that can react with DNA damaging it [63]. The activity of several iron-dependent enzymes can indirectly generate a large amount of ROS, such as superoxide radicals and peroxides. Cytochrome P450 enzymes, nitric oxide synthases, NADPH oxidases and lipoxygenases are the most important enzymes involved in ROS generation $[64,65]$. In normal conditions the antioxidant enzymes, such as glutathione peroxidase, superoxide dismutase and catalases, intervene in detoxifying these ROS [66]. Obviously, the process of ROS generation and detoxification must be strictly balanced to avoid oxidative stress and consequent damage to the iron-containing proteins such as ferritin, DNA damage and in general cellular stress. It is known that ROS accumulation activates different signaling pathways that lead to cell death, such as the apoptosis signal-regulating kinase 1 (ASK1)-p38/c-Jun N terminal kinase (JNK) pathway. Since iron is 
involved in ROS production, it contributes to cell death pathways including apoptosis and necrosis [67]. An important finding was the identification of the ferroptosis, a mechanism of regulated cell death associated with excessive iron levels, and thus production of reactive free radicals, mainly characterized by cytological changes such as decreased mitochondria crista and a damaged outer mitochondrial membrane. For instance, iron attached to membrane phospholipids catalyzes the beginning of lipid peroxidation reactions, which have been correlated with ferroptotic cell death. A crucial regulator of ferroptosis is the glutathione peroxidase 4 (GPX4), which neutralizes lipids derived from cellular metabolism, thus protecting the cells. The direct or indirect inhibition of GPX4 can cause ferroptosis that promotes the antitumor activity of some tumor suppressors (p53, PTEN, pRb) [68]. Even if cancer cells undergo a high oxidative stress maintaining a balanced level of iron, ferroptosis does not often happen in the cancer development. It is known that the activation of Ras-mitogen-activated protein kinase (MEK) signaling can contribute to the sensitivity of cancer cells to ferroptosis, through the abundant presence of iron in cancer resulting from the regulated expression levels of transferrin receptor and ferritin [69]. The ROS- and iron-overload cell death became a new target of therapeutic strategy in several disease, including cancer. Indeed, it has been shown that some ferroptosis-inducing agents, such as erastin or sorafenib, have anti-tumor activity [68].

\subsection{Hemeoxygenase-1 Induction in Cancer Progression}

The electrophilic stimuli, oxidative stress, cellular injury and disease induce the activity of heme-oxigenase 1 (HO-1), a metabolizing enzyme that degrades the pro-oxidant heme into biliverdin/bilirubin, ferrous iron, and carbon monoxide. HO-1 is expressed at basal level in the spleen and liver but it may be induced in other organs following various stimuli (ROS, ipoxia, heat). HO-1 expression is regulated mainly at transcriptional level through the activity of Nrf2, NF- $\mathrm{kB}$, and various oncogenes that can be activated in conditions of oxidative stress. The physiological roles of HO- 1 are iron recycling and maintenance of homeostasis but it is also involved in pathological conditions [70]. It has been demonstrated that, the overexpression of HO- 1 is correlated with a worsening of disease states, as in some types of tumor in which HO-1 is highly expressed by correlating with poor prognosis. In these cases, HO-1 acts as survival molecule and its up-regulation protects cells from apoptosis, induces cell proliferation, metastasis, angiogenesis by promoting vascular endothelial growth factor (VEGF) expression, and resistance to therapy [71]. Numerous papers describe the involvement of HO-1 in the progression of blood malignancies and in the mechanisms leading to chemo-resistance in leukemia, but also in the progression of solid tumors, such as human renal cell carcinoma, melanoma, and prostate- and pancreatic cancer [72]. Particularly, different studies show that HO-1 is expressed in cytoplasm and also in nucleus of cancer cells in lung, prostate and oral tumor tissues. In addition, the positive HO-1 immunoreactivity was detected in stromal compartment, mainly in the tumor-associated macrophages, suggesting that HO-1 may modulate the tumor microenvironment [73]. In non-small cell lung Cancer (NSCLC), the invasive and migratory abilities promoted by high concentrations of glucose increase with the overexpression of HO-1, while decreasing with its silencing [74]. Since an increase of HO-1 expression is associated with migration and invasiveness, a correlation between HO-1 and the occurrence of EMT, a hallmark of metastatic process, has been investigated. In ovarian cancer, EMT is induced by the inhibition of autophagy and the increase of HO- 1 expression and intracellular ROS, whereas the inhibition of HO-1 impairs migration and invasion by inverting EMT [75]. HO-1 may be considered as a novel target for more effective cancer treatments. In this context, it has been demonstrated that pharmacological inhibitors or silencing of HO-1 make tumors more sensitive to therapies, inducing ROS generation and inhibiting tumor growth. Recently, numerous imidazole-based non-porphyrin HO-1 inhibitors were developed. These compounds possess a high selectivity and specificity toward HO-1 and their effective antitumor activity has been demonstrated in vitro and in vivo [76]. On the contrary, notwithstanding in some cases chemo- or radio-therapy contribute to the increase of HO-1 expression, tumor cells expressing high levels of HO-1 are less sensitive to treatment with doxorubicin, cisplatin or gemcitabine in urothelial cancers, cholangiocarcinoma, pancreatic and 
lung cancer cells $[77,78]$. For instance, in pancreatic cancer cells the hypoxic conditions contribute to HO-1 up-regulation, but the inhibition of HO-1 using specific inhibitors under hypoxia reduces cell proliferation, and enhances sensitivity to gemcitabine in vitro. Furthermore, the combined treatment with gemcitabine and HO-1 inhibitors in orthotopic models of pancreatic cancer restrains tumor growth and metastasis formation [79].

\subsection{The Role of Tumor-Associated Macrophages in Iron Metabolism}

A large amount of evidence points to the relevant involvement of macrophages in the regulation of iron metabolism, due to their reprocessing the iron that is released from damaged erythrocytes, and then returning it to circulation $[80,81]$. In general, macrophages in the tumor microenvironment (tumor associated macrophages, TAMs) show an iron-releasing phenotype, which has been traditionally framed in the poor prognostic index associated with a high amount of TAMs [82]. However, being plastic elements, macrophages could be polarized into two main subtypes: The classical M1 and alternative M2 macrophages. Noteworthy, the polarization processes across the two opposite/distinct phenotypes include changes in iron homeostasis, defined by modifications of the expression profile of genes implicated in iron metabolism. The switch across M1 and M2 state involves iron-related phenotypic transitions that favor high (M1) versus low (M2) accumulation of intracellular iron. Thus, M1 macrophages exhibit a phenotype with high level of ferritin and low level of ferroportin, while M2 macrophages show low level of ferritin and high level of ferroportin [83]. The expression of iron-related genes in macrophages is promoted by inflammatory cytokines such as IL-6, IL-10 or bacteria-derived lipopolysaccharide (LPS). In murine macrophages, IL-10 induces HO-1 expression through the p38-mitogen activated protein kinase-dependent pathway (MAPK) and contributes to their polarization. Briefly, the activity of HO-1 with IL-10 contributes to macrophages polarization through a positive feedback loop in which the degradation of heme leads to the production of carbon monoxide (CO) that activates p38 MAPK plus the signal transducer and activator of transcription 3 (STAT3) pathway. They further promote the secretion of IL-10, which in turn induces the expression of HO-1 [84]. In addition, IL-6 and IL-10 induce the expression of CD163, a key membrane protein in macrophages, which acts as an endocytic scavenger receptor that binds hemoglobin in complex with the membrane protein haptoglobin (Figure 2). Moreover, IL-6 or LPS induce the expression of hepcidin in human macrophages, determining an iron preservation phenotype. Upon LPS treatment of M1 macrophage, less iron transporter ferroportin coupled with low CD163 and high levels of ferritin are expressed favoring iron preservation. Conversely, M2 macrophages express high levels of ferroportin and CD163, which cooperate in contrasting ferritin, favoring iron release [85]. This feature is related with the function of CD163, and its involvement in pro-tumor switch of macrophages in cancer progression in humans and mice. Shiraishi et al. demonstrated a macrophage-induced tumor cell proliferation in co-cultures of human monocyte-derived macrophages with sarcoma cell lines, which was specifically abolished by silencing CD163. Furthermore, tumors developed from sarcoma cells in CD163-deficient mice were smaller than those in wild-type mice [86]. Macrophages represent the main component of leukocyte infiltrating the tumor microenvironment and influence the formation, growth and metastasis of tumor by interacting with cancer cells. During tumor progression, M1 macrophages are characterized by supporting the immune system that promotes tumor cell removal and are recruit in the tumors. For instance, the polarization of M1 macrophage prevent the progression of glioblastoma [87]. In response to different stimuli, TAMs can switch to cancer-promoting M2 phenotype, and hence support almost all hallmarks of cancer by producing growth factors, and by contributing to extracellular matrix remodeling. TAMs also provide various factors inducing angiogenesis (such as VEGFA), or metabolism regulators, including c-myc and HIF. It has been demonstrated that HIF can induce an alternative activation of macrophage in glioblastoma, while c-myc is highly expressed in TAMs. [88]. Taken together, these findings explain the crucial role of iron metabolism in the polarization of macrophages and their involvement in cancer through the metabolism of this inorganic ion. To the edge of its relevance in macrophage polarization, one interesting aspect deserving investigation is the 
role possibly exploited by iron with respect to TAMs as treatment target in oncology [89]. In some instance, it has been shown that the density of TAMs at tumor front can predict the responsiveness to chemotherapy. This is the case for colorectal cancer [90], in which the density of CD68+ TAMs interact with chemotherapy in predicting patient outcome, possibly linked to a skew of macrophage polarization toward a M1 anti-tumor role enhanced by 5-fluorouracil, as observed in vitro.

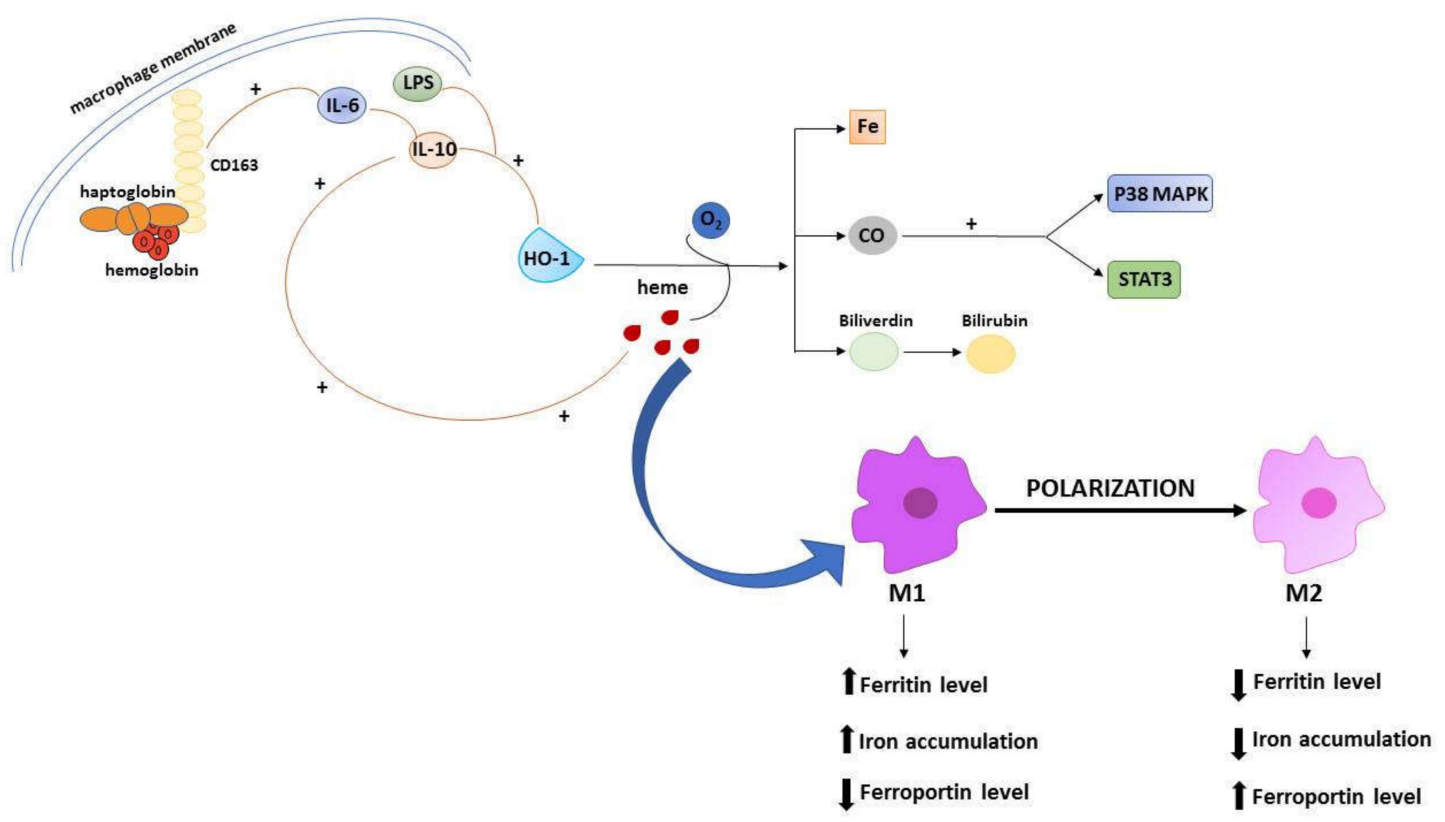

Figure 2. Schematic illustration of the iron-related mechanisms participating in macrophages polarization. The M1 and M2 polarization is accompanied by iron-related phenotypic changes involving ferritin, ferroportin, and iron levels. Macrophages polarization is driven by cytokines activation, such as IL-10 and IL-6. IL-10 induces the activity of HO-1 that oxidizes heme, releasing carbon monoxide (CO), iron and biliverdin. CO activates STAT 3 and p38 MAPK pathways, further promoting the release of IL-10 and the expression of HO-1. IL-6 and IL-10 enhance the expression of CD163 receptor that binds hemoglobin in complex with haptoglobin.

\subsection{Mini-Summary}

In this section, we have underlined the central role of iron in producing ROS and contributing to cell death pathways, such as ferroptosis. Iron-induced free radicals cause oxidative stress and damage to DNA, proteins and cellular organelles, that contribute to the development of cancer. Furthermore, ROS generation induces the activity of the metabolizing enzyme HO-1, involved in the progression of hematologic and solid malignancies. HO-1 expression is detectable also in TAMs, and participates in tuning tumor microenvironment. The studies above-cited support the crucial iron-related mechanisms contributing to macrophage polarization and their supportive role in cancer progression.

\section{Interplay Between Iron Metabolism and Immune System in Tumor}

The role of iron in cancer progression is closely associated with its interferences with the immune response. To control iron availability, macrophages and $\mathrm{T}$ cells can modify their phenotype resembling the mechanisms observed in defense intervention against pathogens, mechanisms which may be activated also at the local tumor level. In fact, cancer cells are themselves as well recognized as foreigners, and immune cells modify their polarization also modulating metabolites involved in iron metabolism.

Accordingly, tumor cells compete with immune cells for iron in the microenvironment in which the pro-inflammatory cytokines promote iron sequestration in macrophages, and induce ROS production as anti-tumor defense response [91]. 
Tumor progression is sustained when cancer cells escape the immune system and/or acquire an immunosuppressive phenotype so that, interacting with tumor-infiltrating immune cells, they promote tumor growth, survival, angiogenesis, and metastasis [92]. As opposed to iron impounding, the anti-inflammatory macrophages and lymphocytes exhibit an iron release phenotype, providing iron in the tumor microenvironment. Therefore, tumor cells are iron users, while lymphocytes and macrophages would act as iron-releasing cells. Moreover, it has been clarified that macrophages are able to secrete ferritin, its expression being found mainly in the stromal compartment in which ferritin promotes tumor growth [93].

The metabolic signature of the microenvironment is responsible for the immunosuppressive nature of tumors. This is related with the polarization of $\mathrm{T}$ cells towards a $\mathrm{T}$ regulatory phenotype which induces an inability of the cellular immune system to effectively mount a T-cell response and, consequently, an exhaustion of $\mathrm{T}$ cell as well as the expression of immune checkpoints such as programmed cell death protein 1 (PD1) [94].

Immunity and metabolism are closely connected. In particular, proteins involved in iron homeostasis may influence lymphocyte populations leading to aberrant ratios of $\mathrm{T}$ cells subsets.

For instance, HFE protein is at the interface of iron metabolism and immune system linking HFE to antigen presentation by major histocompatibility complex class I (MHC-I) molecules [95].

MHC molecules are glycoproteins of the cell surface specialized in presenting antigens to $\mathrm{T}$ lymphocytes. This mechanism initiates an immune response for the elimination of infected or damaged cells by recognizing the foreign antigens. Classical MHC-I molecules are associated with cellular adaptive immunity, while non-classical MHC-I molecules promote an alternative form of immune suppression and surveillance that support both innate and adaptive immune response [96]. HFE is considered a non-classical MHC-Ib, but it has no ability to bind antigens. Nevertheless, HFE is recognized by $\mathrm{T}$ cells and is able to modulate the $\mathrm{T}$ cell population so that $\mathrm{CD} 4 / \mathrm{CD} 8$ ratio is unbalanced in patients with HFE mutations [97].

Generally, non-classical MHC-I molecules have been shown to bind natural killer (NK) cells involved in the innate immune response. In contrast, HFE is not recognized by NK cells and its expression does not modify the reactivity of NK cells. Until now, anomalies in NK populations have not been described in hereditary hemochromatosis [98]. The numerous immune defects reported in $\mathrm{HH}$ patients strongly suggest the relationship between hemochromatosis and modification of the immune response. Iron can influence the phenotype of immune cells and inhibits the surface expression of CD2 and CD4 on T lymphocytes [99]. Several studies on $\mathrm{HH}$ are associated with an increase of CD8+ T cell subsets, such as regulatory CD8+/CD28- T cells, which is coupled with a decrease of CD8+/CD28+ $\mathrm{T}$ cells and diminished activity of cytotoxic $\mathrm{T}$ lymphocytes. Furthermore, the cytokine profiles in $\mathrm{HH}$ patients presented high levels of IL-10 and IL-4 produced by CD8+ T cell subset [100]. Recently, some studies have focused on the impact of the presence of wild-type or mutated HFE on CD8+ T lymphocytes activation. Wild-type HFE inhibits the secretion of $\mathrm{T}$ cell cytokines and the expression of lymphocyte activation markers. This inhibition implicates the $\alpha-1-2$ domains of wild-type HFE and is independent of MHC I expression level [101].

Taken together, these findings suggest an important role of wild-type HFE in altering the reactivity of CD8+ T lymphocytes, probably modulating the antigen immunogenicity.

\section{Mini-Summary}

We can summarize that immune response and iron metabolism are strongly associated in the context of cancer. The tumor-infiltrating immune cells modify their polarization modulating metabolites involved in iron metabolism and interacting with cancer cells to promote tumor growth.

\section{Conclusions}

Iron is involved, in different ways, at various stages of tumor initiation and progression, and contributes to growth and proliferation of cancer cells. Accumulating evidence implicates alterations 
of iron metabolism and ensuing excess of iron as crucial features for cancer development. This aberrant accumulation of iron results in ROS generation and oxidative stress which incurs damage to DNA, proteins and other biomolecules. Variants in HFE gene are associated with deregulation of iron homeostasis lead to hereditary hemochromatosis and to variably increased risks of cancer. However, the association between HFE variants and the development of cancer needs further clarification. Iron is also involved in the modulation of the immune responses, and is seized in macrophages that when showing an iron-releasing phenotype interact with cancer in tumor micro-environment cells to sustain tumor progression.

Author Contributions: S.F. wrote the draft of the manuscript and prepared the original figures. The other members of the writing team, contributed in reviewing and editing the manuscript. All authors have read and agreed to the published version of the manuscript.

Funding: AIRC IG 2018 Id.22234, "H63D variant of the HFE gene as modifier of pancreatic cancer progression: a model for dissecting host immune response".

Conflicts of Interest: The authors declare no conflict of interest.

\section{References}

1. Milto, I.V.; Suhodolo, I.V.; Prokopieva, V.D.; Klimenteva, T.K. Molecular and Cellular Bases of Iron Metabolism in Humans. Biochemistry 2016, 81, 549-564. [CrossRef]

2. Imam, M.U.; Zhang, S.; Ma, J.; Wang, H.; Wang, F. Antioxidants Mediate Both Iron Homeostasis and Oxidative Stress. Nutrients 2017, 9, 671. [CrossRef]

3. Dixon, S.J.; Lemberg, K.M.; Lamprecht, M.R.; Skouta, R.; Zaitsev, E.M.; Gleason, C.E.; Patel, D.N.; Bauer, A.J.; Cantley, A.M.; Yang, W.S.; et al. Ferroptosis: An iron-dependent form of nonapoptotic cell death. Cell 2012, 149, 1060-1072. [CrossRef]

4. Doll, S.; Conrad, M. Iron and ferroptosis: A still ill-defined liaison. IUBMB Life 2017, 69, 423-434. [CrossRef]

5. Bogdan, A.R.; Miyazawa, M.; Hashimoto, K.; Tsuji, Y. Regulators of Iron Homeostasis: New Players in Metabolism, Cell Death, and Disease. Trends Biochem. Sci. 2016, 41, 274-286. [CrossRef] [PubMed]

6. Lv, H.; Shang, P. The significance, trafficking and determination of labile iron in cytosol, mitochondria and lysosomes. Metallomics 2018, 10, 899-916. [CrossRef] [PubMed]

7. Fuqua, B.K.; Lu, Y.; Frazer, D.M.; Darshan, D.; Wilkins, S.J.; Dunn, L.; Loguinov, A.V.; Kogan, S.C.; Matak, P.; Chen, H.; et al. Severe Iron Metabolism Defects in Mice With Double Knockout of the Multicopper Ferroxidases Hephaestin and Ceruloplasmin. Cell. Mol. Gastroenterol. Hepatol. 2018, 6, 405-427. [CrossRef] [PubMed]

8. Wilkinson, N.; Pantopoulos, K. The IRP/IRE system in vivo: Insights from mouse models. Front. Pharmacol. 2014, 5, 176. [CrossRef] [PubMed]

9. Gautam, R.; Wallace, D.F.; Subramaniam, V.N. Hepcidin: Regulation of the master iron regulator. Biosci. Rep. 2015, 35, 1-12. [CrossRef]

10. Dev, S.; Babitt, J.L. Overview of iron metabolism in health and disease. Hemodial. Int. 2017, 21 (Suppl. 1), S6-S20. [CrossRef]

11. Torti, S.V.; Torti, F.M. Iron and cancer: More ore to be mined. Nat. Rev. Cancer 2013, 13, 342-355. [CrossRef] [PubMed]

12. Jung, M.; Mertens, C.; Tomat, E.; Brüne, B. Iron as a Central Player and Promising Target in Cancer Progression. Int. J. Mol. Sci. 2019, 20, 273. [CrossRef] [PubMed]

13. Manz, D.H.; Blanchette, N.L.; Paul, B.T.; Torti, F.M.; Torti, S.V. Iron and cancer: Recent insights. Ann. N. Y. Acad. Sci. 2016, 1368, 149-161. [CrossRef] [PubMed]

14. Torti, S.V.; Torti, F.M. Ironing out cancer. Cancer Res. 2011, 71, 1511-1514. [CrossRef] [PubMed]

15. Zhang, C.; Zhang, F. Iron homeostasis and tumorigenesis: Molecular mechanisms and therapeutic opportunities. Protein Cell 2015, 6, 88-100. [CrossRef]

16. Ludwig, H.; Evstatiev, R.; Kornek, G.; Aapro, M.; Bauernhofer, T.; Buxhofer-Ausch, V.; Fridrik, M.; Geissler, D.; Geissler, K.; Gisslinger, H.; et al. Iron metabolism and iron supplementation in cancer patiens. Wien. Klin. Wochenschr. 2015, 127, 907-919. [CrossRef] 
17. Bystrom, L.M.; Rivella, S. Cancer cells with irons in the fire. Free Radic. Biol. Med. 2015, 79, 337-342. [CrossRef]

18. Zhou, L.; Zhao, B.; Zhang, L.; Wang, S.; Dong, D.; Lv, H.; Shang, P. Alterations in Cellular Iron Metabolism Provide More Therapeutic Opportunities for Cancer. Int. J. Mol. Sci. 2018, 19, 1545. [CrossRef]

19. Adachi, M.; Kai, K.; Yamaji, K.; Ide, T.; Noshiro, H.; Kawaguchi, A.; Aishima, S. Transferrin receptor 1 overexpression is associated with tumour de-differentiation and acts as a potential prognostic indicator of hepatocellular carcinoma. Histopathology 2019, 75, 63-73. [CrossRef]

20. Shen, Y.; Li, X.; Dong, D.; Zhang, B.; Xue, Y.; Shang, P. Transferrin receptor 1 in cancer: A new sight for cancer therapy. Am. J. Cancer Res. 2018, 8, 916-931.

21. Cui, C.; Cheng, X.; Yan, L.; Ding, H.; Guan, X.; Zhang, W.; Tian, X.; Hao, C. Downregulation of TfR1 promotes progression of colorectal cancer via the JAK/STAT pathway. Cancer Manag. Res. 2019, 11, 6323-6341. [CrossRef] [PubMed]

22. Jeong, S.M.; Hwang, S.; Seong, R.H. Transferrin receptor regulates pancreatic cancer growth by modulating mitochondrial respiration and ROS generation. Biochem. Biophys. Res. Commun. 2016, 471, 373-379. [CrossRef] [PubMed]

23. Kim, K.; Mitra, S.; Wu, G.; Berka, V.; Song, J.; Yu, Y.; Poget, S.; Wang, D.N.; Tsai, A.L.; Zhou, M. Six-Transmembrane Epithelial Antigen of Prostate 1 (STEAP1) has a single b heme and is capable of reducing metal ion complexes and oxygen. Biochemistry 2016, 55, 6673-6684. [CrossRef] [PubMed]

24. Whiteland, H.; Spencer-Harty, S.; Morgan, C.; Kynaston, H.; Thomas, D.H.; Bose, P.; Fenn, N.; Lewis, P.; Jenkins, S.; Doak, S.H. A role for STEAP2 in prostate cancer progression. Clin. Exp. Metastasis 2014, 31, 909-920. [CrossRef] [PubMed]

25. Han, M.; Xu, R.; Wang, S.; Yang, N.; Ni, S.; Zhang, Q.; Xu, Y.; Zhang, X.; Zhang, C.; Wei, Y.; et al. Six-Transmembrane Epithelial Antigen of Prostate 3 Predicts Poor Prognosis and Promotes Glioblastoma Growth and Invasion. Neoplasia 2018, 20, 543-554. [CrossRef] [PubMed]

26. Burnell, S.E.A.; Spencer-Harty, S.; Howarth, S.; Bodger, O.; Kynaston, H.; Morgan, C.; Doak, S.H. STEAP2 knockdown reduces the invasive potential of prostate cancer cells. Sci. Rep. 2018, 8, 1-12. [CrossRef] [PubMed]

27. Bian, Z.; Hann, H.W.; Ye, Z.; Yin, C.; Wang, Y.; Fang, W.; Wan, S.; Wang, C.; Tao, K. Ferritin level prospectively predicts hepatocarcinogenesis in patients with chronic hepatitis B virus infection. Oncol. Lett. 2018, 16, 3499-3508. [CrossRef]

28. Wang, X.; An, P.; Zeng, J.; Liu, X.; Wang, B.; Fang, X.; Wang, F.; Ren, G.; Min, J. Serum ferritin in combination with prostate-specific antigen improves predictive accuracy for prostate cancer. Oncotarget 2017, 8, 17862-17872. [CrossRef]

29. Ji, M.; Li, X.D.; Shi, H.B.; Ning, Z.H.; Zhao, W.Q.; Wang, Q.; Zhu, L.N.; Liu, Y.; Wu, C.P. Clinical significance of serum ferritin in elderly patients with primary lung carcinoma. Tumor Biol. 2014, 35, 10195-10199. [CrossRef]

30. Wang, S.L.; Cao, S.; Wu, R.; Chi, F.; Tang, M.Y.; Jin, X.Y.; Chen, X.D. Serum ferritin predicted prognosis in patients with locally advanced pancreatic cancer. Future Oncol. 2015, 11, 2905-2910. [CrossRef]

31. Wang, W.; Knovich, M.A.; Coffman, L.G.; Torti, F.M.; Torti, S.V. Serum Ferritin: Past, Present and Future. Biochim. Biophys. Acta 2010, 1800, 760-769. [CrossRef] [PubMed]

32. Wu, X.N.; Su, D.; Wang, L.; Yu, F.L. Roles of the hepcidin-ferroportin axis and iron in cancer. Eur. J. Cancer Prev. 2014, 23, 122-133. [CrossRef] [PubMed]

33. Shan, Z.; Wei, Z.; Shaikh, Z.A. Suppression of ferroportin expression by cadmium stimulates proliferation, EMT, and migration in triple-negative breast cancer cells. Toxicol. Appl. Pharmacol. 2018, 356, 36-43. [CrossRef] [PubMed]

34. Xue, D.; Zhou, C.X.; Shi, Y.B.; Lu, H.; He, X.Z. Decreased expression of ferroportin in prostate cancer. Oncol. Lett. 2015, 10, 913-916. [CrossRef] [PubMed]

35. Pinnix, Z.K.; Miller, L.D.; Wang, W.; D’Agostino, R., Jr.; Kute, T.; Willingham, M.C.; Hatcher, H.; Tesfay, L.; Sui, G.; Di, X.; et al. Ferroportin and iron regulation in breast cancer progression and prognosis. Sci. Transl. Med. 2010, 2, 43ra56. [CrossRef] [PubMed]

36. Vela, D.; Vela-Gaxha, Z. Differential regulation of hepcidin in cancer and non-cancer tissues and its clinical implications. Exp. Mol. Med. 2018, 50, e436. [CrossRef] 
37. Brookes, M.J.; Hughes, S.; Turner, F.E.; Reynolds, G.; Sharma, N.; Ismail, T.; Berx, G.; McKie, A.T.; Hotchin, N.; Anderson, G.J.; et al. Modulation of iron transport proteins in human colorectal carcinogenesis. Gut 2006, 55, 1449-1460. [CrossRef]

38. Josson, S.; Nomura, T.; Lin, J.T.; Huang, W.C.; Wu, D.; Zhau, H.E.; Zayzafoon, M.; Weizmann, M.N.; Gururajan, M.; Chung, L.W. $\beta 2$-microglobulin induces epithelial to mesenchymal transition and confers cancer lethality and bone metastasis in human cancer cells. Cancer Res. 2011, 71, 2600-2610. [CrossRef]

39. Celesti, G.; Di Caro, G.; Bianchi, P.; Grizzi, F.; Basso, G.; Marchesi, F.; Doni, A.; Marra, G.; Roncalli, M.; Mantovani, A.; et al. Presence of Twist1-positive neoplastic cells in the stroma of chromosome-unstable colorectal tumors. Gastroenterology 2013, 145, 647-657. [CrossRef]

40. Troadec, M.B.; Loréal, O.; Brissot, P. The interaction of iron and the genome: For better and for worse. Mutat. Res. 2017, 774, 25-32. [CrossRef]

41. Feder, J.N.; Gnirke, A.; Thomas, W.; Tsuchihashi, Z.; Ruddy, D.A.; Basava, A.; Dormishian, F.; Domingo, R., Jr.; Ellis, M.C.; Fullan, A.; et al. A novel MHC class I-like gene is mutated in patients with hereditary haemochromatosis. Nat. Genet. 1996, 13, 399-408. [CrossRef] [PubMed]

42. Nemeth, E.; Ganz, T. Regulation of iron metabolism by hepcidin. Annu. Rev. Nutr. 2006, 26, $323-342$. [CrossRef] [PubMed]

43. Schmidt, P.J.; Toran, P.T.; Giannetti, A.M.; Bjorkman, P.J.; Andrews, N.C. The transferrin receptor modulates HFE-dependent regulation of hepcidin expression. Cell Metab. 2008, 7, 205-214. [CrossRef] [PubMed]

44. Powell, L.W.; Seckington, R.C.; Deugnier, Y. Haemochromatosis. Lancet 2016, 388, 706-716. [CrossRef]

45. Alexander, J.; Kowdley, K.V. HFE-associated hereditary hemochromatosis. Genet. Med. 2009, 11, $307-313$. [CrossRef] [PubMed]

46. Pietrangelo, A. Hereditary hemochromatosis: Pathogenesis, diagnosis, and treatment. Gastroenterology 2010, 139, 393-408. [CrossRef] [PubMed]

47. Fargion, S.; Valenti, L.; Fracanzani, A.L. Hemochromatosis gene (HFE) mutations and cancer risk: Expanding the clinical manifestations of hereditary iron overload. Hepatology 2010, 51, 1119-1121. [CrossRef]

48. Cauza, E.; Peck-Radosavljevic, M.; Ulrich-Pur, H.; Datz, C.; Gschwantler, M.; Schöniger-Hekele, M.; Wrba, F.; Hackl, F.; Polli, C.; Gangl, A.; et al. Mutations of the HFE gene in patients with hepatocellular carcinoma. Am. J. Gastroenterol. 2003, 98, 442-447. [CrossRef]

49. Zhang, M.; Xiong, H.; Fang, L.; Lu, W.; Wu, X.; Wang, Y.Q.; Cai, Z.M.; Wu, S. Meta-Analysis of the Association between H63D and C282Y Polymorphisms in HFE and Cancer Risk. Asian Pac. J Cancer Prev. 2015, 16, 4633-4639. [CrossRef]

50. Osborne, N.J.; Gurrin, L.C.; Allen, K.J.; Constantine, C.C.; Delatycki, M.B.; McLaren, C.E.; Gertig, D.M.; Anderson, G.J.; Southey, M.C.; Olynyk, J.K.; et al. HFE C282Y homozygotes are at increased risk of breast and colorectal cancer. Hepatology 2010, 51, 1311-1318. [CrossRef]

51. Robinson, J.P.; Johnson, V.L.; Rogers, P.A.; Houlston, R.S.; Maher, E.R.; Bishop, D.T.; Evans, D.G.; Thomas, H.J.; Tomlinson, I.P.; Silver, A.R. Evidence for an association between compound heterozygosity for germ line mutations in the hemochromatosis (HFE) gene and increased risk of colorectal cancer. Cancer Epidemiol Biomark. Prev. 2005, 14, 1460-1463. [CrossRef] [PubMed]

52. Lv, Y.F.; Chang, X.; Hua, R.X.; Yan, G.N.; Meng, G.; Liao, X.Y.; Zhang, X.; Guo, Q.N. The risk of new-onset cancer associated with HFE C282Y and H63D mutations: Evidence from 87,028 participants. J. Cell. Mol. Med. 2016, 20, 1219-1233. [CrossRef] [PubMed]

53. Chen, W.; Zhao, H.; Li, T.; Yao, H. HFE gene C282Y variant is associated with colorectal cancer in Caucasians: A meta-analysis. Tumor Biol. 2013, 34, 2255-2259. [CrossRef] [PubMed]

54. Agudo, A.; Bonet, C.; Sala, N.; Muñoz, X.; Aranda, N.; Fonseca-Nunes, A.; Clavel-Chapelon, F.; Boutron-Ruault, M.C.; Vineis, P.; Panico, S.; et al. Hemochromatosis (HFE) gene mutations and risk of gastric cancer in the European Prospective Investigation into Cancer and Nutrition (EPIC) study. Carcinogenesis 2013, 34, 1244-1250. [CrossRef]

55. Zhao, Z.; Li, C.; Hu, M.; Li, J.; Liu, R. Plasma ferritin levels, HFE polymorphisms, and risk of pancreatic cancer among Chinese Han population. Tumor Biol. 2014, 35, 7629-7633. [CrossRef]

56. Hucl, T.; Kylanpää-Bäck, M.L.; Witt, H.; Künzli, B.; Lempinen, M.; Schneider, A.; Kemppainen, E.; Löhr, M.; Friess, H.; Ockenga, J.; et al. HFE genotypes in patients with chronic pancreatitis and pancreatic adenocarcinoma. Genet. Med. 2007, 9, 479-483. [CrossRef] 
57. Shen, L.L.; Gu, D.Y.; Zhao, T.T.; Tang, C.J.; Xu, Y.; Chen, J.F. Implicating the H63D polymorphism in the HFE gene in increased incidence of solid cancers: A meta-analysis. Genet. Mol. Res. 2015, 14, 13735-13745. [CrossRef]

58. Lee, S.Y.; Zhu, J.; Salzberg, A.C.; Zhang, B.; Liu, D.J.; Muscat, J.E.; Langan, S.T.; Connor, J.R. Analysis of single nucleotide variants of HFE gene and association to survival in The Cancer Genome Atlas GBM data. PLoS ONE 2017, 12, e0174778. [CrossRef]

59. Laghi, L.; Malesci, A. Microsatellite instability and therapeutic consequences in colorectal cancer. Dig. Dis. 2012, 30, 304-309. [CrossRef]

60. Shi, Z.; Johnstone, D.; Talseth-Palmer, B.A.; Evans, T.J.; Spigelman, A.D.; Groombridge, C.; Milward, E.A.; Olynyk, J.K.; Suchy, J.; Kurzawski, G.; et al. Haemochromatosis HFE gene polymorphisms as potential modifiers of hereditary nonpolyposis colorectal cancer risk and onset age. Int. J. Cancer 2009, 125, 78-83. [CrossRef]

61. Jomova, K.; Valko, M. Advances in metal-induced oxidative stress and human disease. Toxicology 2011, 283, 65-87. [CrossRef] [PubMed]

62. D'Autréaux, B.; Toledano, M.B. ROS as signalling molecules: Mechanisms that generate specificity in ROS homeostasis. Nat. Rev. Mol. Cell Biol. 2007, 8, 813-824. [CrossRef] [PubMed]

63. Marnett, L.J. Oxy radicals, lipid peroxidation and DNA damage. Toxicology 2002, 181, 219-222. [CrossRef]

64. Bedard, K.; Krause, K.H. The NOX family of ROS-generating NADPH oxidases: Physiology and pathophysiology. Physiol. Rev. 2007, 87, 245-313. [CrossRef]

65. Veith, A.; Moorthy, B. Role of cytochrome P450S in the generation and metabolism of reactive oxygen species. Curr. Opin. Toxicol. 2018, 7, 44-51. [CrossRef]

66. Rhee, S.G.; Yang, K.S.; Kang, S.W.; Woo, H.A.; Chang, T.S. Controlled elimination of intracellular $\mathrm{H}(2) \mathrm{O}(2)$ : Regulation of peroxiredoxin, catalase, and glutathione peroxidase via post-translational modification. Antioxid. Redox Signal. 2005, 7, 619-626. [CrossRef]

67. Florean, C.; Song, S.; Dicato, M.; Diederich, M. Redox biology of regulated cell death in cancer: A focus on necroptosis and ferroptosis. Free Radic. Biol. Med. 2019, 134, 177-189. [CrossRef]

68. Mou, Y.; Wang, J.; Wu, J.; He, D.; Zhang, C.; Duan, C.; Li, B. Ferroptosis, a new form of cell death: Opportunities and challenges in cancer. J. Hematol. Oncol. 2019, 12, 34. [CrossRef]

69. Yu, H.; Guo, P.; Xie, X.; Wang, Y.; Chen, G. Ferroptosis, a new form of cell death, and its relationships with tumourous diseases. J. Cell. Mol. Med. 2017, 21, 648-657. [CrossRef]

70. Nitti, M.; Piras, S.; Marinari, U.M.; Moretta, L.; Pronzato, M.A.; Furfaro, A.L. HO-1 Induction in Cancer Progression: A Matter of Cell Adaptation. Antioxidants 2017, 6, 29. [CrossRef]

71. Chiang, S.K.; Chen, S.E.; Chang, L.C. A Dual Role of Heme Oxygenase-1 in Cancer Cells. Int. J. Mol. Sci. 2018, 20, 39. [CrossRef] [PubMed]

72. Li Volti, G.; Tibullo, D.; Vanella, L.; Giallongo, C.; Di Raimondo, F.; Forte, S.; Di Rosa, M.; Signorelli, S.S.; Barbagallo, I. The Heme Oxygenase System in Hematological Malignancies. Antioxid. Redox Signal. 2017, 27, 363-377. [CrossRef] [PubMed]

73. Hsu, F.F.; Yeh, C.T.; Sun, Y.J.; Chiang, M.T.; Lan, W.M.; Li, F.A.; Chau, L.Y.; Lee, W.H. Signal peptide peptidase-mediated nuclear localization of heme oxygenase-1 promotes cancer cell proliferation and invasion independent of its enzymatic activity. Oncogene 2014. [CrossRef]

74. Kim, H.R.; Kim, S.; Kim, E.J.; Park, J.H.; Yang, S.H.; Jeong, E.T.; Park, C.; Youn, M.J.; So, H.S.; Park, R. Suppression of Nrf2-driven heme oxygenase-1 enhances the chemosensitivity of lung cancer A549 cells toward cisplatin. Lung Cancer 2008, 60, 47-56. [CrossRef]

75. Zhao, Z.; Zhao, J.; Xue, J.; Zhao, X.; Liu, P. Autophagy inhibition promotes epithelial-mesenchymal transition through ROS/HO-1 pathway in ovarian cancer cells. Am. J. Cancer Res. 2016, 6, 2162-2177.

76. Greish, K.F.; Salerno, L.; Al Zahrani, R.; Amata, E.; Modica, M.N.; Romeo, G.; Marrazzo, A.; Prezzavento, O.; Sorrenti, V.; Rescifina, A.; et al. Novel Structural Insight into Inhibitors of Heme Oxygenase-1(HO-1) by New Imidazole-Based Compounds: Biochemical and In Vitro Anticancer Activity Evaluation. Molecules 2018, 23, 1209. [CrossRef]

77. Miyake, M.; Fujimoto, K.; Anai, S.; Ohnishi, S.; Nakai, Y.; Inoue, T.; Matsumura, Y.; Tomioka, A.; Ikeda, T.; Okajima, E. Inhibition of heme oxygenase-1 enhances the cytotoxic effect of gemcitabine in urothelial cancer cells. Anticancer Res. 2010, 30, 2145-2152. 
78. Berberat, P.O.; Dambrauskas, Z.; Gulbinas, A.; Giese, T.; Giese, N.; Künzli, B.; Autschbach, F.; Meuer, S.; Büchler, M.W.; Friess, H. Inhibition of heme oxygenase-1 increases responsiveness of pancreatic cancer cells to anticancer treatment. Clin. Cancer Res. 2005, 11, 3790-3798. [CrossRef]

79. Abdalla, M.Y.; Ahmad, I.M.; Rachagani, S.; Banerjee, K.; Thompson, C.M.; Maurer, H.C.; Olive, K.P.; Bailey, K.L.; Britigan, B.E.; Kumar, S. Enhancing responsiveness of pancreatic cancer cells to gemcitabine treatment under hypoxia by heme oxygenase-1 inhibition. Transl. Res. 2019, 207, 56-69. [CrossRef]

80. Soares, M.P.; Hamza, I. Macrophages and Iron Metabolism. Immunity 2016, 44, 492-504. [CrossRef]

81. Recalcati, S.; Locati, M.; Marini, A.; Santambrogio, P.; Zaninotto, F.; De Pizzol, M.; Zammataro, L.; Girelli, D.; Cairo, G. Differential regulation of iron homeostasis during human macrophage polarized activation. Eur. J. Immunol. 2010, 40, 824-835. [CrossRef] [PubMed]

82. Chen, Y.; Song, Y.; Du, W.; Gong, L.; Chang, H.; Zou, Z. Tumor-associated macrophages: An accomplice in solid tumor progression. J. Biomed. Sci. 2019, 26, 1-13. [CrossRef] [PubMed]

83. Agoro, R.; Taleb, M.; Quesniaux, V.F.J.; Mura, C. Cell iron status influences macrophage polarization. PLoS ONE 2018, 13, e0196921. [CrossRef] [PubMed]

84. Sierra-Filardi, E.; Vega, M.A.; Sánchez-Mateos, P.; Corbí, A.L.; Puig-Kröger, A. Heme Oxygenase-1 expression in M-CSF-polarized M2 macrophages contributes to LPS-induced IL-10 release. Immunobiology 2010, 215, 788-795. [CrossRef]

85. Cairo, G.; Recalcati, S.; Mantovani, A.; Locati, M. Iron trafficking and metabolism in macrophages: Contribution to the polarized phenotype. Trends Immunol. 2011, 32, 241-247. [CrossRef]

86. Shiraishi, D.; Fujiwara, Y.; Horlad, H.; Saito, Y.; Iriki, T.; Tsuboki, J.; Cheng, P.; Nakagata, N.; Mizuta, H.; Bekki, H.; et al. CD163 Is Required for Protumoral Activation of Macrophages in Human and Murine Sarcoma. Cancer Res. 2018, 78, 3255-3266. [CrossRef]

87. Guadagno, E.; Presta, I.; Maisano, D.; Donato, A.; Pirrone, C.K.; Cardillo, G.; Corrado, S.D.; Mignogna, C.; Mancuso, T.; Donato, G.; et al. Role of Macrophages in Brain Tumor Growth and Progression. Int. J. Mol. Sci. 2018, 19, 1005. [CrossRef]

88. Aras, S.; Zaidi, M.R. TAMeless traitors: Macrophages in cancer progression and metastasis. Br. J. Cancer 2017, 117, 1583-1591. [CrossRef]

89. Mantovani, A.; Marchesi, F.; Malesci, A.; Laghi, L.; Allavena, P. Tumour-associated macrophages as treatment targets in oncology. Nat. Rev. Clin. Oncol. 2017, 14, 399-416. [CrossRef]

90. Malesci, A.; Bianchi, P.; Celesti, G.; Basso, G.; Marchesi, F.; Grizzi, F.; Di Caro, G.; Cavalleri, T.; Rimassa, L.; Palmqvist, R.; et al. Tumor-associated macrophages and response to 5-fluorouracil adjuvant therapy in stage III colorectal cancer. Oncoimmunology 2017, 6, e1342918. [CrossRef]

91. Schreiber, R.D.; Old, L.J.; Smyth, M.J. Cancer immunoediting: Integrating immunity's roles in cancer suppression and promotion. Science 2011, 331, 1565-1570. [CrossRef] [PubMed]

92. Bindea, G.; Mlecnik, B.; Tosolini, M.; Kirilovsky, A.; Waldner, M.; Obenauf, A.C.; Angell, H.; Fredriksen, T.; Lafontaine, L.; Berger, A.; et al. Spatiotemporal dynamics of intratumoral immune cells reveal the immune landscape in human cancer. Immunity 2013, 39, 782-795. [CrossRef] [PubMed]

93. Kukulj, S.; Jaganjac, M.; Boranic, M.; Krizanac, S.; Santic, Z.; Poljak-Blazi, M. Altered iron metabolism, inflammation, transferrin receptors, and ferritin expression in non-small-cell lung cancer. Med. Oncol. 2010, 27, 268-277. [CrossRef] [PubMed]

94. Munn, D.H.; Bronte, V. Immune suppressive mechanisms in the tumor microenvironment. Curr. Opin. Immunol. 2016, 39, 1-6. [CrossRef] [PubMed]

95. Reuben, A.; Chung, J.W.; Lapointe, R.; Santos, M.M. The hemochromatosis protein HFE 20 years later: An emerging role in antigen presentation and in the immune system. Immun. Inflamm. Dis. 2017, 5, 218-232. [CrossRef]

96. Neefjes, J.; Jongsma, M.L.M.; Paul, P.; Bakke, O. Towards a systems bunderstanding of MHC class I and MHC class II antigen presentation. Nat. Rev. Immunol. 2011, 11, 823-836. [CrossRef]

97. Salter-Cid, L.; Peterson, P.A.; Yang, Y. The major histocompatibility complex-encoded HFE in iron homeostasis and immune function. Immunol. Res. 2000, 22, 43-59. [CrossRef]

98. Pascolo, S.; Ginhoux, F.; Laham, N.; Walter, S.; Schoor, O.; Probst, J.; Rohrlich, P.; Obermayr, F.; Fisch, P.; Danos, O.; et al. The non-classical HLA class I molecule HFE does not influence the NK-like activity contained in fresh human PBMCs and does not interact with NK cells. Int. Immunol. 2005, 17, 117-122. [CrossRef] 
99. Porto, G.; Cruz, E.; Teles, M.J.; De Sousa, M. HFE Related Hemochromatosis: Uncovering the inextricable link between iron homeostasis and the immunological system. Pharmaceuticals 2019, 12, 122. [CrossRef]

100. Costa, M.; Cruz, E.; Oliveira, S.; Benes, V.; Ivacevic, T.; Silva, M.J.; Vieira, I.; Dias, F.; Fonseca, S.; Gonçalves, M.; et al. Lymphocyte gene expression signatures from patients and mouse models of hereditary hemochromatosis reveal a function of $H F E$ as a negative regulator of CD8+ T-lymphocyte activation and differentiation in vivo. PLoS ONE 2015, 10, e0124246. [CrossRef]

101. Reuben, A.; Phénix, M.; Santos, M.M.; Lapointe, R. The WT hemochromatosis protein HFE inhibits CD8 ${ }^{+}$ T-lymphocyte activation. Eur. J. Immunol. 2014, 44, 1604-1614. [CrossRef] [PubMed]

(C) 2020 by the authors. Licensee MDPI, Basel, Switzerland. This article is an open access article distributed under the terms and conditions of the Creative Commons Attribution (CC BY) license (http://creativecommons.org/licenses/by/4.0/). 